\title{
PROPOSTAS DE IDENTIFICAÇÃO NA ÁREA EDUCAÇÃO FÍSICA EM RELAÇÃO AO OBJETO DE ESTUDO
}

\section{ARTIGO ORIGINAL}

NASSAR, Sérgio Eduardo ${ }^{1}$

MOREIRA, Wagner Wey ${ }^{2}$

NASSAR, Sérgio Eduardo, MOREIRA, Wagner Wey. Propostas de identificação na área educação física em relação ao objeto de estudo. Revista Científica Multidisciplinar Núcleo do Conhecimento. Ano 04, Ed. 02, Vol. 01, pp 89-106. Fevereiro de 2019. ISSN: 2448-0959, Link de acesso: https://www.nucleodoconhecimento.com.br/educacao-fisica/propostas-deidentificacao

\section{RESUMO}

Descrever e analisar as propostas de identificação da área de conhecimento científico presentes na EF e Esportes, produzidas nas últimas décadas na visão do docente que atua no Ensino Superior foi objetivo desse estudo desenvolvido com 10 docentes que atuam em instituição pública. Trata-se de uma pesquisa qualitativa, com atitude fenomenológica, tendo como objetivo: Identificar a(s) identidades profissional(is) produzidas na Educação Física. Os dados empíricos foram produzidos por meio de entrevista estruturada, sendo organizados pela Técnica de Elaboração e Análise de Unidades de Significado. O estudo revelou a dificuldade dos professores que atuam na Licenciatura em precisar qual a identidade profissional da área, atribuindo tal realidade à ausência de discussões dessa natureza, desde a sua graduação até a vida profissional.

${ }^{1}$ Doutor em Educação, Professor Adjunto II.

2 Livre Docência e Doutor em Educação, Professor Titular III. 
Palavras-chave: Identidade Profissional Docente, Licenciatura em Educação Física, Docência Superior.

\section{INTRODUÇÃO}

O percurso histórico da área vem provocando, nos cursos de licenciatura em Educação Física (EF), uma crise de identidade "[...] considerando o longo tempo de indefinição da mesma enquanto possibilidade científica" (MOREIRA, 2012, p. 113). Essa crise também atingiu os cursos técnicos em EF que visam o treino desportivo mesmo no âmbito escolar.

Enquanto as aulas de Educação Física propiciam primeiramente o pensar e, por conseguinte, a realização dos movimentos, o ensino da técnica esportiva é de forma mecanizada, sem incentivar a criatividade nas diversas ações que o corpo pode realizar. As atividades e os exercícios repetitivos visam a melhora da performance com intuito de treinamento específico em contextos diferenciados daqueles apreendidos na formação inicial.

Nossa intenção de pesquisa objetivou em descrever e analisar as propostas de identificação da área de conhecimento científico presentes na EF e Esportes, produzidas nas últimas décadas na visão do docente que atua no Ensino Superior.

Assim, decorremos a seguir a identidade da área EF, bem como as propostas apresentadas para este campo, e que visam apontar para uma possível identidade. Os argumentos para a temática são apoiados pelos estudos: a Teoria AntropológicoCultural do Esporte e da EF, de José Maria Cagigal; a Teoria Praxiológica, de Pierre Parlebás; a Teoria Psicocinética, de Jean Le Boulch; a Ciência da Motricidade Humana, proposta por Manoel Sérgio e, por fim, a Ciência do Desporto, discutida por Jorge Olímpio Bento ${ }^{[3]}$. 


\section{MÉTODO}

O aporte metodológico deste artigo é de abordagem qualitativa porque se preocupa em analisar e interpretar a complexidade do comportamento humano (SEVERINO, 2007). O caráter qualitativo da pesquisa advém das vivências percebidas e expressas que os sujeitos trazem consigo.

A pesquisa fundamentada na abordagem qualitativa de atitude fenomenológica tem seu objeto de conhecimento no mundo vivido pelo sujeito. A fenomenologia ${ }^{[4]}$ parte do cotidiano, da compreensão do mundo de viver e entender, buscando resgatar os significados atribuídos pelo sujeito ao fenômeno que está sendo estudado, e não a busca de definições e conceitos previamente pensados (REZENDE, 1990; GIL, 2008).

O locus eleito para a pesquisa foi a Faculdade de EF do Campus de Castanhal, da Universidade Federal do Pará. Os sujeitos participantes da pesquisa foram 10 docentes entrevistados, graduados em EF e vinculado ao curso de Licenciatura da Faculdade de Educação Física.

Quanto à formação acadêmica em pós-graduação, assim se apresentam os titulados: 5 docentes doutores e 6 mestres, sendo que destes, 4 professores estão em processo de doutoramento, com titulação nas seguintes áreas do conhecimento: Educação, EF, Antropologia, Bioengenharia e Medicina com ênfase em doenças tropicais.

Para conhecer a trajetória desses docentes em relação ao campo da pesquisa, perguntamos sobre a sua formação continuada, tanto em cursos de especialização Lato Sensu, quanto em pós-graduação Stricto Sensu, que consiste no mestrado e doutorado.

O instrumento de pesquisa foi a entrevista estruturada com questões direcionadas que buscaram compreender o fenômeno estudado. Na entrevista, interrogamos o sujeito por meio da questão geradora: Qual(is) identidade(s) profissional(is) você assume enquanto professor no Curso de EF?. 
Para a realização dessa etapa, partimos para um contato prévio com os possíveis sujeitos, apresentando os objetivos da pesquisa, formalizando o convite e esclarecendo sobre o Termo de Consentimento Livre e Esclarecido (TCLE).

Quanto a técnica de pesquisa nos apoiamos na Técnica de Elaboração e Análise de Unidades de Significado (MOREIRA; SIMÕES; PORTO, 2005), resultante da junção de duas envergaduras: a Análise do Fenômeno Situado visa a descrição, redução e interpretação dos dados, que resulta nas Unidades de Significado; e a Análise de Asserção Avaliativa busca identificar as atitudes dos sujeitos em relação ao objeto do qual falam.

A técnica utilizada apresenta três momentos: o relato ingênuo, a identificação de atitudes e a interpretação das informações sob a forma de discursos orais e escritos, que são vistos como indicadores significativos que atuam sobre a fala.

\section{REFERENCIAL TEÓRICO}

Queremos enfatizar aqui que há propostas de identidade para área, além do objeto de estudo da Educação Física. Essa crise de identidade profissional da EF e de seu objeto de estudo tem a ver com o que Dubar (2009, p.25) defende, quando uma área tem sua identidade indefinida: isso "[...] provoca uma crise que traz para área de conhecimento configurações de discursos, de atitudes, de narrativas puramente contingentes, totalmente dependentes de seu contexto de produção", o que ocorre nesta área.

Entendemos que, em todo esse percurso evolutivo da área, possivelmente já obtivemos pistas que apontaram uma identidade para este campo de estudo, e apresentamos, a seguir, 5 teorias que são relevantes para a compreensão do objeto de estudo da EF e sua identidade própria.

A primeira que apresentamos é a Teoria Antropológico-Cultural do Esporte e da EF, de José Maria Cagigal[5]. Com oito obras publicadas referentes à EF e Esporte, da sua produção acadêmica, analisamos as Obras Selectas, volume I, II e III, para a 
compreensão do que o autor busca explicitar sobre o entendimento de EF e de Desporto $^{[6]}$ enquanto área de conhecimento científico.

No volume I, traz uma explanação sobre o Homem e o Esporte, principalmente sobre a história das olimpíadas, os jogos, o homo ludens e desportivus, o profissionalismo e o esporte espetáculo, a educação e o esporte, os valores educativos, o adolescente, a família e a escola. Dialoga ainda sobre o desporto, a pedagogia e o humanismo, na defesa de uma filosofia e de uma psicopedagogia para a EF, tendo o desporto e seu dinamismo social como fator de integração entre adolescentes.

No volume II, o autor retrata o esporte e seu impulso para o nosso tempo, com destaque para: a saúde mental, a perspectiva do futuro, as questões do ócio, do atleta e da derrota, bem como a psicologia do esporte na sociedade atual, com destaques para a implicação, a classificação e a organização deste fenômeno. Apresenta ainda a cultura intelectual e física, o esporte e a educação, as bases antropo filosóficas para a EF e a ênfase nos elementos teóricos para diagnosticar o desporto.

Por fim, no volume III, o autor abrange o esporte como espetáculo e ação, em discussão ampla sobre as formas, o corpo, a educação, a cultura física entre outros pontos. Traz uma visão sobre a cultura física e seu relacionamento com o ser humano, o nosso tempo e os riscos da contemporaneidade do esporte. Há um capítulo muito interessante denominado " $O$ Oh Deporte! (anatomía de un gigante)", em que aponta caminhos pelos quais o esporte beneficia o ser humano, com o desenvolvimento social, a alternativa de vida, o humanismo e, principalmente, a força original que tem o esporte na vida de uma pessoa.

Notamos que a definição de jogo para Cagigal é muito mais abrangente do que habitualmente conhecemos. Ele o compreende a partir do divertir, brincar, expressar, representar em todas as manifestações humanas.

É uma ação livre, espontânea e desinteressada que faz parte da vida cotidiana e que acontece em uma limitação tanto temporária quanto espacial, seja por determinação de regras ou não. Destaca ainda a questão do homo ludens e do homo desportivus, 
tendo Huizinga (1980, p.29) como referência, ao afirmar que toda e qualquer natureza do ser humano se expressa na face, o que proporciona, nas palavras do autor, "[...] un salmo de armonía y ritmo", entendendo o lúdico enquanto dinamismo, manifestação e representação na vida do ser humano. O homo desportivus deve ser compreendido como desportivo: essa é a essência humana que cada um apresenta frente aos valores intelectuais, artísticos, espirituais, materiais e até referentes ao desporto.

Ao tratar do desporto, da pedagogia e do humanismo, Cagigal (1996) insiste no diálogo que a EF há de ter com as disciplinas que envolvem a formação do ser humano, sendo que o enfoque deve visar todas, de forma igualitária, e não somente aquelas das dimensões físicas, como vem sendo visto o trato com o corpo nos cursos de graduação da área, ao longo do tempo.

É interessante constatar que, desde o início de seus estudos, já enfatizava que a EF precisava pensar na sua filosofia própria, sendo necessário adotar princípios filosóficos para ser compreendida e entendida enquanto ciência. A EF, enquanto concepção para o autor, é compreendida como uma arte, uma ciência, um sistema de técnicas que podem ajudar o ser humano a desenvolver todas as suas potencialidades para um diálogo harmonioso com a vida, mas, sobretudo, com atenção especial à sua própria natureza.

No segundo volume de suas Obras Selectas, reflete sobre a pergunta: La Educación Física ¿Ciencia?, inclusive apontando sugestões, a partir da Psicologia Evolutiva, para a programação da EF.

O objeto próprio da EF se concretiza no ser humano em movimento ou enquanto capaz de movimentar-se, mas a partir de sua cultura. Nessa perspectiva da Teoria Antropológico-Cultural do Esporte e da EF, entendemos que possivelmente tenhamos ingredientes necessários para que ela possa ser considerada uma ciência, pois a área encontra o seu objeto de estudo próprio. 
Sugere que a EF pense nas bases antropo filosóficas para a área, adote os princípios antropológicos para elaboração de uma cultura física contemporânea. Para tanto, destaca alguns elementos básicos: 1) perceber que o ser humano começa no mundo que o rodeia a partir da ideia de ser corpo "entidad corporal" corporeidade, ou seja, no contato com o mundo por meio de questões sensoriais, perceptivas, temporais, pensadas a partir do corpo; 2) a consciência de que o homem vive em movimento, que o corpo faz parte da sua vida e não é uma parte física do ser humano (CAGIGAL, 1996).

Pela visão do autor, acreditamos que suas propostas, reflexões e conceitos são pertinentes à área da EF, sugerindo que o esporte deva ser uma atividade prévia à organização social e que traga possibilidade aos sujeitos de participação e não de exclusão, a ponto de extirpar de muitos a vontade e o prazer de uma vida ativa.

Outra identidade apontada foi a Teoria Praxiológica, de Pierre Parlebás ${ }^{[7]}$, que apresenta uma Ciência denominada de Praxiologia Motriz, e tem como proposta um "estudo coerente e unitário agrupando todos os dados pertinentes que dizem respeito ao seu objeto específico [...], visando constituir um campo, o campo da ação motriz" (PARLEBÁS, 1988, p. 173). Tem também várias publicações em diversos idiomas.

Acredita que a EF deva ter seu enfoque na Teoria Sociomotriz, desenvolvendo como estudo os jogos desportivos institucionais e os esportivos tradicionais, para analisar o valor e a dinâmica de cada modalidade. No final da década de 1960, inicia suas primeiras publicações sobre a Praxiologia: lá se vão mais de trinta anos para desvendar o mundo dos jogos, esportes, brincadeiras e exercícios físicos.

$\mathrm{Na}$ ação psicomotriz, há a necessidade de uma relação interativa que precisa, então, ser entendida enquanto sociomotriz. A ação psicomotriz tem enfoque dirigido à pessoa que desenvolve suas capacidades físicas e intelectuais por meio do movimento, interagindo com o outro.

Pensar na ação motriz por meio dos jogos desportivos tradicionais, exercícios físicos, atividades livres e pelo movimento, tem relação com o que Parlebás considera como 
a identidade, a unidade e a especificidade da EF enquanto prática pedagógica, que é uma compreensão da lógica intrínseca das ações motrizes.

Na sua obra, Parlebás (1999) enfatiza a dinâmica de interações dos jogadores nos jogos; apresenta o entendimento das redes de sistemas, comunicações e códigos presentes no jogo, o que define como "gramática do jogo". Entende que a práxis no desporto é a lógica do jogo que guia as ações motrizes que, consequentemente, propiciam a incorporação do discurso pelo sujeito. Afirma que o esporte é reflexo e, ao mesmo tempo, produtor de normas sociais que acontecem por meio dos contatos corporais, do controle e do domínio, e, principalmente, pelas relações afetivas e relacionais que surgem na prática desportiva.

Sustenta que o profissional da área EF, ao orientar a prática de um jogo, propicia relações significativas entre os praticantes, com o meio, os materiais e, essencialmente, com os outros. Nessa direção, Parlebás (1999) propõe o grupo de ação sociomotriz: a) grupo de interação sociomotriz de antagonismo: que são aquelas atividades que contêm adversários; b) grupo de interação sociomotriz de cooperação: quando os participantes se complementam e colaboram nas atividades, como nas atividades em duplas.

Ressalta um significado fundamental das condutas motoras e afetivas, principalmente com ênfase no plano da interação entre os participantes de uma atividade. Sabemos que, em uma aula com diversas pessoas, não é o movimento somente que se encontra em pauta, mas as relações, os sorrisos, os contatos, as expressões que fazem parte do contexto de ser humano (NASSAR, 2004).

Para Parlebás (1999, p.119), o objeto de estudo da EF seria a conduta motriz, e a área deve ser entendida como:

[...] um campo da pedagogia das condutas motrizes, por meio de uma prática de intervenção e influência sobre as condutas motrizes dos participantes em função das normas educativas implícitas ou explícitas. 
A teoria de Parlebás (1988) ressalta que a função deste professor visa a orientação da prática do jogo, ou seja, intervenção a todo momento, propiciando relações que tenham significado na vida dos praticantes e não apenas o jogar por jogar; que os sujeitos envolvidos, enquanto atores e espectadores, possam usufruir daquilo que o jogo proporciona ao ser humano.

Destacamos também a Teoria Psicocinética, de Jean Le Boulch ${ }^{[8]}$ com foco no desenvolvimento global das potencialidades de uma pessoa, que não se resume tão somente ao aspecto motor; tanto que analisou o desenvolvimento orgânico e emocional que se refletem na identidade e nas qualidades das relações do ser humano.

A educação motora estabeleceria uma ciência independente para a EF, denominada de Teoria Psicocinética ou Ciência do Movimento, centrada no desenvolvimento da pessoa, e estaria vinculada à Ciência da Educação.

Para Le Boulch (1995, p. 14), há a educação do movimento e a educação pelo movimento. A educação do movimento visa a eficácia do ser humano "a aquisição dos comportamentos motores desejados faz-se em favor de certas relações precisas entre as reações do organismo e os estímulos do meio reforçados pela atribuição metódica". Quando ressalta a educação pelo movimento, direciona a três pontos: a conduta funcional, o entendimento do organismo como sistema e a análise funcional. Para o autor, o movimento deveria se tornar um meio para a educação, um fio condutor para moldar a unidade do ser humano tanto corporal quanto mentalmente.

A respeito da educação pelo movimento, adota a concepção funcional da Teoria Psicocinética que traz a ideia da conduta funcional que "apoia-se nas ciências humanas e biológicas com a finalidade de aperfeiçoar as condições do desenvolvimento da pessoa [...] vê a pessoa como uma totalidade em relação ao seu meio" (LE BOULCH 1995, p. 16). Compreende a relação do sujeito e da situação e, a partir daí, a conduta da psicomotricidade funcional tem sua sustentação pela experiência corporal e mental que é vivida pelo sujeito. 
Le Boulch compreende que a EF deveria ter outra denominação, ou seja, Educação Motora, mesmo esse termo não sendo novo, pois, desde o final da década de 1952, ele é citado nos textos publicados por Dr. J. Philippe, na Revue Philosophique, e, a partir de 1961, surge a primeira formação teórica sobre uma EF científica, publicada nos Cahiers Scientifiques d'Éducation Physique (LE BOULCH, 1995).

O autor define a Psicocinética ou Ciência do Movimento Humano como "uma ciência aplicada ao desenvolvimento da pessoa [...] sua situação natural seria, portanto no quadro das ciências da educação [...] uma ciência de concepção funcional" (LE BOULCH, 1995, p. 15-16).

Segundo De Marco (1995), mais do que mudar o nome da EF, a preocupação seria contribuir com o desenvolvimento pleno das pessoas, com a formação de uma consciência crítica, o desenvolvimento da consciência corporal, propiciando a descoberta do seu próprio corpo, como ressalta a seguir:

O conceito de movimento precisa ser revisto e ampliado, tem que ser considerado como um conjunto de diversos processos; sensação, cognição, emoção e memória, cuja síntese pode resultar em movimento ou na motricidade, como capacidade singular da espécie humana (DE MARCO, 1995, p. 33).

O principal destaque é a proposta de mudança da EF do olhar do corpo objeto para o próprio corpo, por meio da aprendizagem motora. Compreende que é necessária uma atitude que corresponda à reação global de um organismo unitário, autônomo frente às situações determinadas de organização de condutas motrizes.

Destacamos a Ciência da Motricidade Humana (MH), defendida por Manuel Sérgio Vieira e Cunha ${ }^{[0]}$, tem o propósito de dar um corte epistemológico no racionalismo, do qual nasceu a EF, e que está definitivamente ultrapassado.

Afirma que a EF é a pré-história da Ciência da Motricidade Humana e que deve estudar o ser humano que se movimenta intencionalmente na direção da 
autossuperação. Sua tese volta o olhar ao ser humano, precisamente ao corpo. No campo da EF, percebemos nitidamente o corpo fragmentado, descontextualizado, manipulado, modelado, característico do paradigma cartesiano.

Os apontamentos de Descartes direcionam ao mecanismo corpóreo-físico-natural e, principalmente, ao seu racionalismo, que adentrou a área da EF e que tem como objeto o corpo que, na sua forma de pensar, fez brotar o cientismo e o positivismo.

O pensamento cartesiano, no método da razão tradicional, considera o corpo enquanto físico, mas para a MH estar em movimento é sinal de esperança em nível existencial, e não somente motor ou físico. Para isso é preciso passar do físico para a motricidade (SÉRGIO, 1999).

$\mathrm{Na}$ esteira desse argumento, recorremos a Moreira (2012, p. 119), quando discorre que:

[...] ao associar o corpo humano a uma máquina, mais precisamente a um relógio, Descartes propiciou o estabelecimento de uma ciência que passou a tratar o corpo como uma máquina que pode ser analisada em termos de desempenho de suas peças [...] O método cartesiano produziu e ainda continua produzindo progressos espetaculares em certos setores com resultados fascinantes [...] pelo qual grande parte dos pesquisadores das áreas biológicas e médicas não se preocupam com as limitações da abordagem reducionista.

Pensar em um corte epistemológico é superar o paradigma cartesiano e adentrar o paradigma da complexidade. A MH é a teoria de uma prática, a qual se transformará na prática de uma teoria.

O autor propõe identificar o objeto de estudo da EF, só lembrando que ele é um objeto em construção e não construído. Sabemos que a área é hibrida, busca seus pilares de sustentação em tantas outras áreas de conhecimento, mas, nesta caminhada, esqueceu-se de pensar epistemologicamente e identificar seu objeto de estudo. 
Sérgio (1999) aponta que os objetivos da MH são habituar o aluno a pensar de forma radical, crítica e sistêmica; é uma ciência que visa desconstruir a ideia da prática como critério de verdade na prática pedagógica, sendo que a prática sem teoria direciona o aluno a uma rotina; é compreender que ela pode ser uma ciência autônoma, por meio do movimento intencional em busca da transcendência e da superação.

A Ciência da Motricidade Humana, explica o sentido de transcendência ${ }^{[10]}$ que significa "o que está além, ou fora, da realidade dada, daquilo que naturalmente pode operar-se [...] o ser humano na sua motricidade, prova que é um ente que anseia pela transcendência, pela capacidade de ser melhor" (SÉRGIO, 1995 p. 165).

Jogar, dançar, lutar, praticar esportes sem perder de vista a busca da transcendência ou da autossuperação, preocupando-se com a convivência mesmo na competição, e realizar tudo isso por vontade própria, com intencionalidade, não alteraria o quadro de valores praticados no dia a dia da EF, enquanto área de conhecimento e disciplina curricular.

Por fim, descrevemos a Ciência do Desporto, de Jorge Olímpio Bento ${ }^{[11]}$ que de forma bela e poética, o autor traz, em seus escritos, um jeito de filosofar que faz o leitor questionar tudo aquilo que o perturba à sua volta, como ressalta: "é o olhar para o alto, para fora e além de nós, à procura de uma referência e um ponto de apoio que permitam sobre pulsar a realidade" (BENTO, 2012, p.13), exercitando, assim, a autonomia e a liberdade de filosofar por meio de reflexões que apresentam experiências vivenciadas e a realidade.

Quanto à Ciência do Desporto, Bento (2006, p. 155) a define como "um conjunto de tecnologias corporais, sendo o uso destas balizado por razões e padrões culturais e por intencionalidades, metas e valorizações sociais", além de nos alertar que a sociedade pós-moderna, via novas tecnologias, está se caracterizando por imprimir nos corpos humanos afisicidade ${ }^{[12]}$, aumentando o predomínio da mente sobre o corpo, da atividade mental sobre a motora. 
O desporto visa cuidar do corpo, da alma e de tudo aquilo que seja direcionado à dimensão humana, tanto nas questões do seu interior quanto do exterior, do individual quanto do coletivo, do objetivo e do subjetivo, possibilitando o que Moreira (2006) perspectiva: o envolvimento com a arte de viver e conviver.

Bento (2004) ressalta que o desporto tem conceito representativo, agregador, sintetizador e unificador de dimensões biológicas, físicas, motoras, lúdicas, corporais, técnicas e táticas, culturais, mentais, espirituais, psicológicas, sociais e afetivas.

Estudar a Ciência do Desporto é ir além da institucionalização como área específica de formação, investigação, produção e divulgação científica, e do significado das organizações, e como elas se constituem e se organizam no mundo, mas, a preocupação em analisar a influência que o desporto exerce na corporeidade e no estilo de vida, visa torná-lo um projeto de arte.

Nessa esteira, a Ciência do Desporto propõe a necessidade de ampliar o olhar para a função de humanização do desporto, tornando-se palco no qual o corpo é ator principal e interlocutor que se relaciona com dimensões de outras áreas de conhecimento.

Segundo Bento (2004), na sociedade atual, vivemos um novo mandamento em relação ao corpo: "comerás o pão ganho com o suor do teu rosto" (p.65), aplicandose isso ao desporto e às atividades corporais, mandamento aprendido e praticado por grande parte dos professores da EF.

Entendemos que os cursos de formação inicial em EF, enquanto área de possível campo de conhecimento, correm o risco de não galgar ao patamar de área científica autônoma, de não conseguir identificar as possibilidades de clarear seu objeto de estudo em consequência da falta de aprofundamento nas dimensões conceituais e nas bases epistemológicas que são apresentadas por muitos docentes nos cursos de graduação. Bento (2012, p. 80) complementa que o Desporto deve ser "palco da competição humana onde se revelam qualidade e avanços, um esforço universal de melhoria da condição humana". 


\section{ANÁLISE E DISCUSSÃO}

É necessário localizar o objeto de estudo da área numa defesa epistemológica das teorias mencionadas anteriormente neste artigo - Teoria Antropológico-Cultural do Esporte e da EF, Teoria Praxiológica, Teoria Psicocinética, Ciência da Motricidade Humana e Ciência do Desporto.

Quando os professores apontam interpretações diferentes para suas identidades profissionais, como no caso dos entrevistados, isso se traduz no que Dubar (2009) defende de que uma área que não tem a sua identidade definida inicia uma crise que proporciona formas de discursos, atitudes, narrativas analisadas isoladamente do seu contexto de produção.

Ao analisar o discurso dos sujeitos, nosso estudo vem desvelar se os professores do curso de graduação têm conhecimento das propostas de identificação da área, produzidas nas últimas décadas, e investigar a identidade profissional apresentada nos discursos dos docentes.

Há mais de 70 anos já foi proposta uma identidade para área da EF, mas os vários docentes que atuam nos cursos das mais diversas localidades deste Brasil não aprofundaram as discussões que visam culminar a identidade deste campo de atuação.

Relatamos sobre a Teoria Antropológico-Cultural do Esporte que mostra como objeto de estudo da área o ser humano em movimento ou capaz de movimentar-se, e as relações sociais direcionadas às suas aptidões e atitudes. $O$ ponto central desta proposta segue por duas vertentes: a adaptação ao meio físico e ao espaço; e a integração ao meio social (CAGIGAL, 1996).

Após analisarmos os discursos dos sujeitos, foi possível identificar que os docentes 3 , 4, 7 e 8 se aproximam da proposta de Cagigal, mas não demonstram conhecimento sobre o que autor propõe e nem mesmo afinidade com leituras e discussões sobre a proposta para área da EF. 
Na sequência, relatamos a Teoria Praxiológica proposta por Parlebás (1988). Identificamos que a proposta tem o foco nos jogos esportivos, a partir de dois olhares: tradicionais e esportivos, como apresentamos.

Dos sujeitos da nossa pesquisa, notamos que os docentes 1 e 2, em nossa percepção, são os que mais se aproximaram desta teoria, uma vez que os dados não demonstraram explicitamente que não comungam com esta proposta.

Referimo-nos, a seguir, à Teoria Psicocinética de Le Boulch $(1995 ; 1998)$ que tem como objeto de estudo o ser humano em movimento, na dialética das suas relações com o físico e o humano, numa semelhança entre o sujeito e seu universo vivido.

Nos discursos, não encontramos nenhum docente demonstrando afinidade ou enraizamento na teoria apresentada por Le Boulch.

Em seguida, dissertamos sobre a Ciência da MH, proposta por Sérgio (1995; 1999; 2003; 2008), apropriando-se da ideia que o ser humano deve ser visto em sua totalidade. Ele define que a $\mathrm{MH}$ )(MHvisa compreender e explicar as ações motoras que estudam a energia para o movimento intencional, buscando especialmente a transcendência e a superação.

Nos discursos dos docentes, identificamos que o sujeito 6 assume a $\mathrm{MH}$ como base epistemológica, tanto na sua identidade profissional como para o curso de EF, não se distanciando desta proposta que considera coerente com o projeto maior do curso, o PPC.

Por outro lado, o discurso do docente 5 apresenta sinais desta teoria, mesmo sem assumi-la totalmente, apesar de ser da área biológica, provavelmente sem conhecimento das propostas de Sérgio (1995; 1999; 2003; 2008).

Ressaltamos que, como professores que atuam na docência superior, acreditamos que a Ciência da $\mathrm{MH}$, dentre as teorias apresentadas, torna-se essencial para a área da EF. Somos docentes que vimos trazendo essa discussão para dentro da sala de 
aula, sem medo de arriscar que ela apresenta o objeto de estudo mais concreto para o campo de atuação.

E por fim, referimo-nos à Ciência do Desporto, discutida por Bento (2004; 2006; 2012), o desporto que visa cuidar do corpo, da alma e de tudo o que está direcionado à dimensão humana, tanto nas questões do interior quanto do exterior, do individual quanto do coletivo, do objetivo e do subjetivo.

Nos discursos, não conseguimos enquadrar as representações identitárias dos sujeitos 9 e 10 em nenhuma teoria a respeito das propostas de identificação para área.

Um estudo realizado por Allain e Coutinho (2017) também aponta controversas na formação profissional de docentes relatando que à uma contra identidade na formação dos futuros profissionais de biologia, convergindo com nossos achados.

Oliveira (2000) conclui que os cursos de Licenciatura em EF, na formação inicial, necessitam remodelar a atuação na escola, rever o campo da profissão liberal pela qual a sociedade anseia, e que os docentes no campo da formação propiciem mudanças sociais e uma produção de conhecimento nas novas áreas de atuação.

\section{CONCLUSÕES}

É relevante a riqueza encontrada nos dados da pesquisa em cena, uma vez que nos entender a complexidade da identidade do docente que atua no Ensino Superior. Mas concluímos que os docentes, sujeitos da pesquisa, têm dificuldade em reconhecer a própria identidade e o objeto de estudo da EF.

Em nosso modo de ver, o objeto de estudo é o corpo em movimento (grifo nosso), por meio das suas condutas motoras, dos movimentos e práticas corporais, que apontam a superação e as intencionalidades próprias de cada ser humano, além de um olhar humanista para o trato com os conteúdos que envolvem os jogos, a dança, as lutas, as ginásticas e os esportes. 
Concluímos, em nosso artigo que a área da EF por não ter objeto de estudo próprio que sustente uma identidade profissional, transita por um estado de crise epistemológica, que resvala na prática pedagógica dos docentes já que reproduzem, geralmente, conteúdos oriundos de sua formação acadêmica inicial e dos diálogos que estabelecem com concepções teórico-metodológicas distintas das assumidas no Projeto Pedagógico do Curso.

\section{REFERÊNCIAS}

ALLAIN, L.R.; COUTINHO, F.A. Controvérsias emt orno das identidades profissionais de licenciados em Biologia: um estudo inspirado na teoria ator-rede. Educação em Revista. Belo Horizonte, MG: 2017, vol 33, Enpud.

BENTO, J. O. Desporto: discurso e substância. Universidade do Porto, Porto: Campo Letras editores, 2004. Coleção Saberes do desporto.

, J. O. Corpo e Desporto: reflexões em torno desta relação. In: MOREIRA, W. W. (Org.) Século XXI: A era do corpo ativo. São Paulo: Papirus, 2006.

, J. O. Pelo regresso do desporto: ensaio epistemológico. In: BENTO, J. O.; MOREIRA, W. W. Homo Sportivus: O humano no homem. Belo Horizonte: Instituto Casa da Educação Física, 2012, p. 14-112.

CAGIGAL, J. M. Obras Selectas. Volumes I, II e III. Comitê Olímpico Español e Asociación Española de Deportes para Todos. Madrid: Cadiz, 1996. 1206 p.

DE MARCO, A. Pensando a educação motora. 2 ed. Campinas, SP: 1995 (Coleção Corpo \& Movimento).

DUBAR, C. A crise das identidades: Interpretação de uma mutação. São Paulo: Editora USP, 2009. 279 p.

DUPOND, P. Vocabulário de Merleau-Ponty. São Paulo: WMF Martins Fontes, 2010. 80 p. 
FRANYUTI, M. L. S., La concepción pedagógica de Pierre Parlebás. 2009. Disponível em: $<$ http://www.cpar.sep.gob.mx/dgef/htmlecturas/Otras/pierre_parlebas.html> Acesso em: 06 set. 2004.

GIL, A. C. Métodos e técnicas de pesquisa social. 6 ed. São Paulo: Atlas, 2008.

HUIZINGA, J. Homo Ludens: o jogo como elemento da cultura. 2 ed. São Paulo: Perspectiva, 1980.

LE BOULCH, J. O conceito de educação motora. In: DE MARCO, A. Pensando a educação motora. Campinas, SP: 1995, p.11 -26 (Coleção Corpo \& Movimento).

, J. El cuerpo em la escuela en el siglo XXI. Espana, INDE Publicaciones, 1998.

MOREIRA, W. W. Formação Profissional em Ciência do Esporte: Homo Sportivus e Humanismo. In: BENTO, J. O.; MOREIRA, W. W. Homo Sportivus: O humano no homem. Belo Horizonte: Instituto Casa da Educação Física, 2012, p. 111-172.

W. W.; SIMÕES, R.; PORTO, E. Análise de conteúdo: técnica de elaboração e análise de unidades de significado. Revista Brasileira Ciência e Movimento, v. 14, n 4, p. 104 -114, 2005.

NASSAR, S. E. O corpo idoso nas atividades aquáticas: o significado para os praticantes. 2004. 120f. Dissertação (Mestrado) - Universidade Metodista de Piracicaba, Unimep, Programa de Pós-graduação em Educação Física, Piracicaba, 2004.

OLIVEIRA, A. A. B. de. Mercado de trabalho em Educação Física e a formação profissional: breves reflexões. Revista Brasileira Ciência e Movimento, Brasília, v.8, n.4, p. 45-50, set., 2000. 
PARLEBÁS, P. Elementos de Sociologia del Deporte. Malaga: Universidad Internacional Deportiva de Andalucia, 1988.

P. Jeux, sports et sociétes: lexique de praxéologie motrice. Paris: Instituto du sport et de l'éducation physique, 1999.

REZENDE, A. M. de. Concepção fenomenológica da Educação. São Paulo, Cortez: Autores Associados, 1990.

SÉRGIO, M. Motricidade Humana: contribuições para um paradigma emergente. Blumenau, SC: Furb, 1995 (Coleção Epistemologia e Sociedade). 155 p.

, M. Um corte epistemológico: da Educação Física à Motricidade Humana. 2 ed. Lisboa: Instituto Piaget, 1999.

, M. Alguns olhares sobre o corpo. Lisboa: Instituto Piaget, 2003. 150 p.

, M. A racionalidade epistêmica na Educação Física do século XX. In: SÉRGIO, M.; ROSÁVRIO, T.; FEITOSA, A. M.; ALMADA, F; VILELA, J.; TAVARES, V. O Sentido e a Ação. Lisboa: Instituto Piaget, 2008, p. 13 -30.

SEVERINO, A. J. Metodologia do trabalho científico. 23 ed. São Paulo: Cortez, 2007.Neste texto, nos posicionamos epistemologicamente na defesa da Ciência da Motricidade Humana e na Ciência do Desporto.

\section{APÊNDICE - REFERÊNCIAS DE NOTA DE RODAPÉ}

1. Fenomenologia é o estudo das essências, ou seja, essência da percepção da consciência (REZENDE, 1990).

2. Diretor do Instituto Nacional de Educación Física de Madrid, Espanha, e presidente da Escola Superior de EF (Écoles Normales Supérieures d' Education Physique), França. 
3. No decorrer do texto, grafaremos as palavras desporto e esporte como sinônimas, sendo desporto utilizado quando as referências são do contexto espanhol, e esporte quando associadas ao contexto português.

4. Professor de EF, sociólogo, psicólogo, linguista francês, dirigiu durante vinte anos o Instituto Nacional de Desporto da França; atualmente é responsável pelo Laboratório de Jogos Desportivos e Ciências da Ação Motriz na Faculdade de Sociologia da Universidade de Sorbonne, em Paris, França (FRANYUTI, 2004).

5. Professor e médico estudioso dos sistemas cerebrais e das relações com as funções motoras, tendo apresentado suas obras na década de 1970.

6. Manuel Sérgio pertence à célula dos escritores do Partido Comunista Português. Estudou, com rigor, teóricos como Marx, Nietzsche e Freud. É licenciado em Filosofia pela Universidade Clássica de Lisboa e Doutor e Professor Agregado em Motricidade Humana, pela Universidade Técnica de Lisboa e do Curso de EF do Instituo Piaget, de Almada. É sócio da Associação Portuguesa de Escritores e autor e coautor de 40 livros e de inúmeros artigos, em revistas nacionais e estrangeiras. É professor catedrático convidado aposentado da Faculdade de Motricidade Humana da Universidade Técnica de Lisboa. Foi professor catedrático da Universidade Fernando Pessoa e do Instituto Superior da Maia, e ainda da Faculdade de Educação de Física da Universidade Estadual de Campinas. É sócio fundador da Sociedade Internacional de Motricidade Humana e da Sociedade Portuguesa de Motricidade Humana.

7. Dupond $(2010,71)$ diz que a transcendência "designa ao mesmo tempo a abertura do sujeito para o mundo, denominada de 'transcendência ativa', e a opacidade do mundo, que é inseparável de sua realidade [...] transcendência ativa da consciência, o movimento pelo qual ela se joga numa coisa e no mundo ou na direção do outro". Para o autor esse conceito de transcendência faz eco com o percurso de Heidegger, pois a transcendência "[...] não está ausente do movimento, sendo retirada do sujeito [...] se torna uma estrutura intraontológica do mundo" (Ibid, p. 72). 
8. Professor Catedrático da Faculdade de Ciências do Desporto e da EF da Universidade do Porto, Portugal pertence à cadeira de Pedagogia do Desporto. Foi Pró-Reitor da Universidade do Porto, e atualmente é Presidente do Conselho Diretivo da referida Faculdade, sendo responsável pelos cursos de Licenciatura e Mestrado na área de Pedagogia do Desporto.

9. Formas de trabalho e vida que ignoram a dimensão física, corporal e motora do homem.

Enviado: Fevereiro, 2018

Aprovado: Fevereiro, 2019 